\title{
Anti-inflammatory protein TNFa-stimulated gene-6 (TSG-6) reduces inflammatory response after brain injury in mice
}

Kazadi Nadine Mutoji

University of Houston

Mingxia Sun

University of Houston

Amanda Nash

University of Houston

Sudan Puri

University of Houston

Vincent Hascall

Cleveland Clinic

Vivien J Coulson-Thomas ( $\square$ vcoulsonthomas@gmail.com )

University of Houston

\section{Research}

Keywords: TSG-6, glial scar, astrocytes, glycosaminoglycans and inflammation

Posted Date: April 20th, 2020

DOI: https://doi.org/10.21203/rs.3.rs-22505/v1

License: (c) (i) This work is licensed under a Creative Commons Attribution 4.0 International License.

Read Full License 


\section{Abstract}

Background: Current research suggests that the glial scar surrounding penetrating brain injuries is instrumental in preserving the surrounding uninjured tissue by limiting the inflammatory response to the injury site. We recently showed that (TNF)-stimulated gene-6 (TSG-6), a well-established anti-inflammatory molecule, is present within the glial scar. We hereby investigate the role of TSG-6 within the glial scar.

Methods: TSG-6 null and littermate control mice were subjected to penetrating brain injuries, after which the injury site and remaining injured hemisphere were analyzed. The presence of activated astrocytes, inflammatory markers and glial scar components were evaluated by real-time PCR and immunohistochemistry.

Results: Our findings demonstrate that mice lacking TSG- 6 present a more severe inflammatory response after injury, which is correlated with an enlarged area of astrogliosis beyond the injury site.

Conclusion: Our data provides evidence that TSG-6 has an anti-inflammatory role within the glial scar.

\section{Background}

Traumatic brain injury (TBI) is a major medical concern that affects over 10 million people in the world each year $(1,2)$. A variety of injuries can cause TBI leading to a variety of injury severities (3-6). With improved medical interventions over the years the mortality rate due to TBI has decreased, culminating in a significant population living with the long-term effects of TBI. It is well accepted that in addition to the immediate effects of TBI there are also multiple potential long-term gradually evolving sequelae that are influenced by the type of injury, severity of injury and medical interventions at the time of injury $(7,8)$. Additionally, a link between mild traumatic brain injuries and Alzheimer or chronic traumatic encephalopathy has long been suspected (9). At present, long term effects of repeated TBI have been seen in multiple sports-related injuries, including post-traumatic parkinsonism, post-traumatic dementia and chronic post-concussion syndrome (10-13). Thus, studying the short and long-term consequences of TBI at a cellular and molecular level may lead to a new understanding and perhaps better long-term management of such injuries via new and/or refined treatment strategies.

Astrogliosis is a hallmark of TBI, which commences hours after injury and leads to an abnormal increase in the number of activated astrocytes in and around the injury site $(14,15)$. Immediately after injury (acute phase), astrocytes become highly proliferative and up-regulate the production of extracellular proteins, culminating in the formation of a glial scar, which impedes axonal growth, and therefore inhibits neuronal regeneration $(14,16-19)$. The intensity of the reactive astrogliosis directly affects the immediate and longterm effects of $\operatorname{TBI}(6,15,20,21)$. Penetrating brain injuries (PBIs) cause direct parenchymal laceration, neuronal cell loss and hemorrhage, which lead to focal tissue damage at the injury site. Astrogliosis is triggered after PBIs and forms astrocyte-rich scar tissue surrounding the injury site (22-24). Mounting evidence shows that reactive astrocytes surrounding the injury site are instrumental in preserving the surrounding uninjured tissue by forming scar borders, which separate damaged and inflamed tissue from 
adjacent viable neural tissue $(14,15,20,25-29)$. Reactive astrocytes up-regulate intermediary filament proteins, Glial Fibrillary Acidic Protein (GFAP) and vimentin (VIM), as well as, increase production of chondroitin sulfate proteoglycans (CSPGs), all of which have been implicated in glial scar formation (3035). Indeed, deficiency of both GFAP and VIM ( $\left.\mathrm{Gap}^{-/-} \mathrm{Vim}^{-/}\right)$leads to defective and less organized glial scarring in mice (34-36). Moreover, Wilhelmsson et al. observed that $\mathrm{GfapP}^{-/-} \mathrm{Vim}^{-/-}$mice exhibited increased axonal regrowth post injury in comparison to the wild-type control, suggesting that loss of these two proteins is enough to prevent glial scar formation and promote some neuronal regeneration (34). However, whether these mice present improved functional recovery compared to their littermates remains to be established. Recent work by the Sofroniew group has shown that scar tissue bordering the injury site is necessary for limiting inflammation and tissue damage to the injury site $(26,37)$. Moreover, data from Hermann et al. show that GFAP-driven ablation of STAT3 in astrocytes leads to the loss of lesion demarcation and subsequent glial scar formation, and, in turn, results in increased invasion of inflammatory cells into adjacent viable tissue and further spread of inflammation (38). This suggests that early demarcation from the glial scar formed by astrocytes restricts movement of inflammatory cells located within the lesion site into adjacent healthy tissue, thereby restricting tissue damage to the injury site. There is currently a significant number of studies investigating how reactive astrocytes regulate and limit inflammation in the injury site and which cellular components and major pathways play a part in this process $(16,37,39-41)$.

(TNF)-stimulated gene-6 (TSG-6) is a 35-kDa protein that is secreted by a wide range of cell types in response to inflammatory mediators and growth factors (42). Originally identified as a gene product induced in fibroblasts by TNF (12), TSG-6 contains a link module domain that mediates interaction with the polysaccharide hyaluronan (HA) as well as other glycosaminoglycans (GAGs), which have served as targets in past experiments in attempts to promote neuronal regeneration after CNS injury (43-46). We recently identified that TSG-6 is expressed in the central nervous system (CNS), where it catalyzes the transfer of HCs from Inter-a-Inhibitor (Ial, also known as ITI) onto HA, forming a specialized HA/HC/TSG-6 matrix within the glial scar (47-52). This HA/HC/TSG-6 matrix is monocyte-adhesive and is found in most, if not all, inflammatory processes $(53,54)$. These TSG-6 modified HA matrices bind inflammatory cells, and the interaction of these cells with the HA matrices modulates their responses, which are central to pathological inflammation (55-61). Therefore, we postulate that TSG-6 could participate in the formation of an immunosuppressive environment within the glial scar. Thus, the main objective of this study was to have a better understanding of the role TSG6 plays in the glial scar. Our findings demonstrated that TSG-6 null mice present a more severe inflammatory response after injury when compared to littermate control mice. This increased inflammatory response is correlated with an enlarged area of astrogliosis beyond the injury site.

\section{Methods}

\section{TSG6 null $\left(\mathrm{TSG6}^{-/-}\right)$or heterozygous $\left(\mathrm{TSG6}^{+} /^{-}\right)$mice and animal maintenance}


Transgenic Tsg-6 null mice (Tnfip $6^{\Delta / \Delta}$ ) hereafter referred to as $T s g-6^{-/-}$mice and heterozygous mice, hereafter referred to as $T s g-6^{+/-}$mice, were maintained as previously described (52). Experimental procedures for handling the mice were approved by the Institutional Animal Care and Use Committee, University of Houston. Heterozygous mice have previously been shown to display no phenotype and therefore were used as littermate controls in our study (52).

\section{Brain Injury}

Mice (7 to 8 weeks of age) were anesthetized with ketamine $(80-100 \mathrm{mg} / \mathrm{kg}$ - Vedco INC, Catalog\# 07890-8598) and xylazine (5-10 mg/Kg, Akorn INC, Catalog\# 07-808-1947) by IP injection and allowed to go into full anesthetic state. A sterile surgical drill (Precision Tools, Model Craft PPV2237) was used to make a hole of approximately $1.5 \mathrm{~mm}$ in diameter in the skull over the right cortex, and $2 \mathrm{~mm}$ parallel to the midline. A 30-gauge needle (Exel, Catalog \#26437) was then used to puncture through the corpus collosum. After injury, the skin at the surgical site was closed with two sutures. The area was then cleaned with $70 \%$ percent ethanol, and mice were placed on a heating pad and monitored until they regained consciousness prior to being transferred to a clean cage. Mice were monitored daily and none showed any decrease in weight $\geq 15 \%$ when compared to their pre-surgical weight. Mice were euthanized at 1, 3 and 5 days post injury to study the acute effects of brain injury, and at 10 and 14 days to study long-term chronic effects.

\section{Perfusion fixation and brain tissue processing}

Brain samples were collected at $1,3,5,10$, and 14 days post injury for immunohistochemistry analyses. Briefly, mice were initially injected with a lethal dose of combined anesthetics, ketamine and xylazine. Once mice were under deep anesthesia, abdominal excisions were performed to expose the heart, which was used to perfuse $2 \%$ formalin (Fisher Scientific, Catalog\#SF100-4) throughout the whole body via a gravity-driven flow system for whole body fixation. Subsequently, the brain was isolated from the skull and further immerse fixed for 2 days in 2\% paraformaldehyde (Electron Microscopy Sciences, Catalog\#15710). For cryosection processing, brains were immersed in 30\% sucrose for 2 days and embedded in OCT embedding medium (Fisher Healthcare, Catalog\#4585), frozen, and $10 \mu \mathrm{m}$ sections obtained. The sections were mounted on superfrost slides (VWR, Catalog\#48311-703) and stored at $-20^{\circ} \mathrm{C}$ until use.

\section{Immunohistochemistry}

Upon use, the slides were heated at $65^{\circ} \mathrm{C}$ for 30 minutes, and subsequently, sections were washed with PBS to remove tissue freezing medium. Sections were then treated with $0.1 \%$ glycine (Fisher Chemical, Catalog\#G46-500), blocked with 5\% FBS (Seradigm, Catalog\#3100 - 500) and permeabilized with $0.1 \%$ saponin prepared in PBS. Sections were then incubated with the primary antibodies anti-Tenascin (Abcam, Ab108930) and anti-GFAP (Abcam, Ab4647). Sections were washed and incubated with appropriate secondary donkey antibodies conjugated with Alexa Fluor ${ }^{\circledR} 488$ (Life Technologies) or Alexa Fluor ${ }^{\circledR} 555$ (Life Technologies) for one hour at $18^{\circ} \mathrm{C}$. For HA staining, tissues were incubated with biotinylated HA binding protein (385911, Millipore) followed by NeutrAvidin ${ }^{\circledR}$ Alexa 555 (Life Technologies). The tissues were then washed and nuclei stained with 4,6-diamidino-2-phenylindole (DAPI, Sigma-Aldrich). Sections 
were mounted in Prolong ${ }^{\circledR}$ Gold (Molecular Probes) and imaged using a ZEISS LSM 800 Confocal microscope with Airyscan. The images were analyzed using Zen Software (Zeiss). Multiple z-stack tiles were captured and frames were processed together (using the stitching mode followed by full orthogonal projection) into a single image. Secondary controls were done with a goat IgG isotype control (ab37388; Abcam) in place of the primary antibody and did not yield any significant staining (results not shown).

\section{RNA extraction from brains and real-time PCR analysis}

Brains collected from injured mice at 1, 5 and 10 days post injury were used for RNA extraction. Briefly, mice were euthanized and brain tissue was immediately isolated from each mouse. Injury sites (A samples) were dissected from the rest of the injured right hemisphere, transferred into a labeled Eppendorf tube and immediately immersed in liquid nitrogen. The remaining right hemisphere brain tissue $(B$ samples) from each animal was transferred into a different tube and also frozen as described. The samples were kept at $-80^{\circ} \mathrm{C}$ until RNA extraction. Total RNA was isolated from these tissue samples using Trizol® Reagent (Invitrogen, Carlsbad, CA) and chloroform extraction (Sigma-Aldrich, Catalog\#650498). First strand cDNA was reverse transcribed using 1.5 to $2 \mu \mathrm{g}$ of total RNA and the high capacity cDNA Reverse Transcription kit (Applied Biosystems, catalog\# 4368814, lot 00593854) according to the manufacturer's instructions. Quantitative real-time PCR amplification was performed on $1 \mu \mathrm{l}$ or $50 \mathrm{ng}$ of the cDNA (1:5) using the PowerUp SYBR Green Master Mix kit (Applied Biosystems, Catalog\# A25918) in a CXF Connect Real-time System from BIO-RAD, using an activation cycle of $95^{\circ} \mathrm{C}$ for 10 min, 40 cycles of $95^{\circ} \mathrm{C}$ for 15 seconds and $60^{\circ} \mathrm{C}$ for $1 \mathrm{~min}$. A complete list of primers used in this study is shown in Table 1. Gene expression levels were normalized against $A c t b$ and Gapdh using the $2^{-\Delta C t}$ and/or $2^{-\Delta \Delta C t}$ methods. 
Table 1

\begin{tabular}{|c|c|c|c|}
\hline $\begin{array}{l}\text { Gene } \\
\text { (Mus } \\
\text { musculus) }\end{array}$ & $\begin{array}{l}\text { accession } \\
\text { number }\end{array}$ & Forward $\left(5^{\prime} 3^{\prime}\right)$ & Reverse ( $\left.5^{\prime} 3^{\prime}\right)$ \\
\hline $\begin{array}{l}\text { Tenascin } \\
C(\operatorname{tnc})\end{array}$ & NM_011607.3 & CCAGGGTTGCCACCTATTT & GTCTAGAGGATCCCACTCTACTT \\
\hline Gfap & NM_001131020.1 & AACAACCTGGCTGCGTATAG & TCTCGAACTTCCTCCTCATAGAT \\
\hline $\begin{array}{l}\text { Tsg-6 } \\
\text { /Tnfaip6 }\end{array}$ & NM_009398.2 & CCCACATGCAAAGGAGTGTG & TGAGCCGAATGTGCCAGTAG \\
\hline Chst1 & NM_021439.2 & CACCCAGTCATGCGGAGGAA & GCAGGATGGCAGTGTTGGAT \\
\hline Chst12 & NM_021528.3 & GAGCTGGAGAACGAAGAGTTT & CAGGAGGTACTGGATGAAGTTG \\
\hline$I L 1 \beta$ & NM_008361.4 & GTGCAAGTGTCTGAAGCAGC & СTCATCACTGTCAAAAGGTGGC \\
\hline Cspg4 & NM_139001.2 & TCTACAGCTCCTGCCTCCTT & ATGTGGAGAACTGGAGCAGC \\
\hline $\begin{array}{l}\text { Ccl5 } \\
\text { (Rantes) }\end{array}$ & NM_013653.3 & СCTCACCATATGGCTCGGAC & ACGACTGCAAGATTGGAGCA \\
\hline$N f k b 1$ & NM_008689.2 & GTCACCCATGGCACCATAAA & ССТTСАССТTСАGТTTССТTСТС \\
\hline Has 1 & NM_008215.2 & $\begin{array}{l}\text { CTA TGC TAC CAA GTA TAC } \\
\text { CTC G }\end{array}$ & $\begin{array}{l}\text { TCT CGG AAG TAA GAT TTG } \\
\text { GAC }\end{array}$ \\
\hline Has2 & NM_008216.3 & $\begin{array}{l}\text { CGG TCG TCT CAA ATT CAT } \\
\text { CTG }\end{array}$ & $\begin{array}{l}\text { ACA ATG CAT CTT GTT CAG } \\
\text { CTC }\end{array}$ \\
\hline Has 3 & NM_008217.4 & $\begin{array}{l}\text { GAT GTC CAA ATC CTC AAC } \\
\text { AAG }\end{array}$ & СCC АCT AAT ACA TTG CAC AC \\
\hline Itih1 & & $\begin{array}{l}\text { CCA CCC CAT CGG TTT TGA } \\
\text { AGT GTC T }\end{array}$ & $\begin{array}{l}\text { TGC CAC GGG TCC TTG CTG } \\
\text { TAG TCT }\end{array}$ \\
\hline Itih2 & & $\begin{array}{l}\text { ATG AAA AGA CTC ACG TGC } \\
\text { TTT TTC }\end{array}$ & ATT TGC CTG GGG CCA GT \\
\hline Itih3 & & $\begin{array}{l}\text { TGA GGA GGT GGC CAA CCC } \\
\text { ACT }\end{array}$ & CGC TTC TCC AGC AGC TGC TC \\
\hline Actb & NM_007393.5 & CACTGTCGAGTCGCGTCC & TCATCCATGGCGAACTGGTG \\
\hline Gapdh & NM_001289726.1 & AACAGCAАСTСССАСТСТTC & CCTGTTGCTGTAGCCGTATT \\
\hline
\end{tabular}

\section{Statistical analysis}

All values are presented as the mean \pm standard deviation of the mean. The difference between the two groups was compared by means of the Student's t-test. $P \leq 0.05$ was considered to be statistically significant. Statistical analysis was performed using the GraphPad Prism version 7 software package (GraphPad Software, San Diego, CA, USA). 


\section{Results}

\section{TSG-6 expression after PBI}

In order to investigate whether TSG-6 is present in the glial scar after brain injury we analyzed the expression profile of Tsg 6 in the injury site and injured hemisphere before and after a PBI in $T s g-6^{+/-}$mice (Fig. 1A). There was a 2-fold increase in Tsg-6 expression 5 days after injury when compared to naïve mice. There was a further increase in Tsg-6 expression over time after injury, with expression increasing 2 fold from 5 to 10 days after injury (Fig. 1A). Interestingly, we did not find a difference in the expression levels of Tsg- 6 between the injury site and the remaining hemisphere, indicating that Tsg-6 expression is not contained solely to the injury site (Fig. 1A). Therefore, there is also an increase in Tsg-6 expression in the surrounding tissue after injury.

\section{Analysis of astrocyte recruitment after PBI}

We assessed the level of astrogliosis in the injury site and in the remaining injured hemisphere by quantifying the levels of GFAP ${ }^{+}$astrocytes using real-time PCR (Fig. 1B and C). For such, we isolated mRNA from the injury site and remaining injured hemisphere 1 and 5 days after injury of $T s g-6^{-/-}$and $T s g$ $6^{+/-}$mice. Both $T s g-6^{-/-}$and $T s g-6^{+/-}$mice presented an increase in the levels of GFAP in the injury site when compared to the remaining injured hemisphere, which corroborates the literature. $\mathrm{Tsg}_{-} \mathrm{6}^{-/-}$mice showed a significant increase in GFAP levels within the injury site at both 1 and 5 days post-injury when compared to $T s g-6^{+/-}$mice (Fig. 1B and C). This data indicates that $T s g-6^{-/-}$mice have more astrocytes in the injury site when compared to $T s g-6^{+/-}$mice. At 5 days after injury there was a significant increase in GFAP expression in the injured hemisphere of $T s g-6^{-/-}$mice compared to $T s g-6^{+/-}$mice, indicating that $\mathrm{Tsg}^{-6^{-/-}}$mice present astrogliosis beyond the injury site.

\section{The effect of TSG-6 on the secretion of inflammatory markers after PBI}

The inflammatory response was also assessed in $T s g-6^{-/-}$and $T s g-6^{+/-}$mice 1,5 and 10 days post-injury by quantifying the expression levels of $N F K B$, Rantes and $I L 1 \beta$ (Fig. 2). Higher expression levels of $N F K B$, Rantes and $I L 1 \beta$ were detected in $T s g-6^{-/-}$mice when compared to $T s g-6^{+/-}$mice during the acute phase after injury. Specifically, a 2.5-fold and 3-fold increase in $N f_{K} b$ expression was found in the injury site and remaining injured hemisphere, respectively, in $T s g-6^{-/-}$mice compared to $T s g-6^{+/-}$mice 5 days after injury (Fig. 2B). 10 days after injury there was still a significant increase in $N f_{K} b$ expression in the surrounding hemisphere of $T s g-6^{-/-}$mice when compared to $T s g-\sigma^{+/-}$mice (Fig. 2C). No significant differences were found in the expression of $\mathrm{NfKb}$ between $T s g-6^{-/-}$and $T s g-6^{+/-}$mice 1 day after injury (Fig. 1A). The levels of $\mathrm{Ccl} 5$ (Rantes) were also assessed 1, 5 and 10 days post-injury. There was a significant increase in the expression of Rantes in the injured hemisphere of $T s g-6^{-/-}$mice when compared to $\mathrm{Tsg}-6^{+/-}$mice (a 4-fold increase) 5 days after injury; however, no difference was found 
between $T s g-6^{-/-}$and $T s g-6^{+/-}$mice 1 and 10 days after injury (Fig. 2D-F). IL $1 \beta$ levels were increased in the injury site of $T S G-6^{-/-}$mice when compared to $T s g-6^{+/-}$mice at 1-day post-injury (Fig. 2G). At 5 days post-injury a 3 -fold and 4 -fold increase in the expression of $I L 1 \beta$ were noted in the injury site and remaining injured hemisphere, respectively, of $T s g-6^{-/-}$mice when compared to $T s g-6^{+/-}$mice (Fig. $2 \mathrm{H}$ ). At 10 days post-injury a 2.5 -fold increase in the expression of $I L 1 \beta$ was noted in the injury site of $T s g-6^{-/-}$ mice when compared to $\mathrm{Tsg}_{-} \mathrm{6}^{+/-}$mice (Fig. 2I).

\section{The effect of TSG-6 on the secretion of glial scar components after PBI}

We also evaluated glial scar secretion within the injury site and injured hemisphere by evaluating the expression levels of the biosynthetic enzymes responsible for HA and CS chain elongation, specifically hyaluronan synthase 2 (Has2), carbohydrate (chondroitin 4) sulfotransferase (chst 11) and carbohydrate (chondroitin 4) sulfotransferase 12 (chst 12) (Fig. 3). Has2 expression increased in the injury site when compared to the remaining injured hemisphere 5 days post injury in both $T s g-6^{+/-}$and $T s g-6^{-/-}$mice, confirming the numerous previously published reports showing that HA is an integral component of the glial scar. Interestingly, there was a 2-fold increase in Has2 expression in the injury site of $T s g-6^{-/-}$mice when compared to $T s g-6^{+/-}$mice 5 days after injury, indicating that there is a higher rate of glial scar production in $\mathrm{Tsg}_{-} \mathrm{\sigma}^{-/-}$mice when compared to $\mathrm{Tsg}-\mathrm{\sigma}^{+/-}$mice (Fig. 3A). At 10 days after injury, Has2 expression is still increased by 2 -fold in $T s g-6^{-/-}$mice when compared to $T s g-6^{+/-}$mice; however, at this time point there is also an increase in Has2 expression in the remaining injured hemisphere of $\mathrm{Tsg}^{-\mathrm{C}^{-/-}}$ mice when compared to $\mathrm{Tsg}-\mathrm{6}^{+/-}$mice (Fig. 3B). Therefore, at 10 days after injury, in $\mathrm{Tsg}-\mathrm{6}^{-/-}$mice, the expression of glial scar components was no longer limited to the injury site, and, instead, was also present within the remaining injured hemisphere. Interestingly, this is also true for the expression of Chst11 and Chst12, which show a 5-fold and 4-fold increase, respectively, within the injured hemisphere of $\mathrm{Tsg}^{-6^{-/-}}$ mice at 5 days post injury when compared to $\mathrm{Tsg}^{-6^{+/-}}$mice (Fig. $3 \mathrm{C}$ and E). The increase in Chst 11 and Chst12, in both the injury site and injured hemisphere, was maintained through to 10 days post-injury (Fig. 3D and F).

\section{The effect of TSG-6 on astrocyte activation and recruitment after PBI}

In order to further investigate the process of astrogliosis in $T s g-6^{+/-}$and $T s g-6^{-/-}$mice, injured brains were harvested and processed for histology. Sections were stained for GFAP in order to assess the distribution of astrocytes in and around the injury site and also throughout the remaining brain tissue. The number of astrocytes was counted within the injury site, throughout the injured hemisphere and also throughout the contralateral hemisphere 3 and 14 dpi (days post-injury - Fig. 4A and B). At 3 and 14 dpi there is a significant increase in the number of astrocytes within the injury site when compared to the injured hemisphere and contralateral hemisphere in both $T s g-6^{+/-}$and $T s g-6^{-/-}$mice. At 3 dpi there is no 
significant difference between the number of astrocytes within the injury site between $T s g-{ }^{+/-}$and $T s g-6^{-/}$ - mice; however, there was a significant increase in the number of astrocytes within the injured hemisphere in $\mathrm{Tsg}_{-6^{-/-}}$mice when compared to $\mathrm{Tsg}-\mathrm{6}^{+/-}$mice (Fig. $4 \mathrm{~A}$ ). At 14 dpi there was a significant increase in the number of astrocytes within the injury site and injured hemisphere in $T s g-6^{-/-}$mice when compared to Tsg- $6^{+/-}$mice (Fig. 4B and D). The increase in the distribution of astrocytes can be seen beyond the injury site in $\mathrm{Tsg}_{-6^{-/-}}$mice (Fig. $4 \mathrm{C}$ and Div).

\section{Discussion}

Chondroitin sulfate proteoglycans (CSPGs) are well established as major ECM components in the central nervous system (62). Over a decade ago, Silver et al. identified that CSPGs within the glial scar inhibited axonal growth, and this triggered a great deal of interest in targeting CS within the scar tissue as a means to promote axonal regeneration $(32,63-65)$. Over the years, strategies utilizing the enzymes chondroitinase $\mathrm{ABC}(\mathrm{Ch} A \mathrm{BC})$ and $\mathrm{ChAC}$ have been used to remove the CS component of the glial scar as a means to promote axonal growth and regeneration (43, 44,66-69). Many studies have shown that specifically removing CS within the glial scar is enough for axons to grow across the injury site $(63,64,70$, 71). However, significant regeneration was never observed, and many groups found limited or no improvement after targeting CS within the glial scar (63). One known unique characteristic of TSG-6 is its known ability to bind to a number of ligands including HA, CS and core proteins of proteoglycans (i.e. versican and aggrecan), forming specific HA/HC/TSG-6 matrices $(57,72-76)$. Our previous study suggests these HA/HC/TSG-6 matrices could also support the glial scar (47). Therefore, given that TSG-6 directly binds to both CS and HA, these enzymatic treatments targeting the glial scar as a means to promote regeneration would also remove TSG-6, a known anti-inflammatory molecule that is also a component of the glial scar (74). This could, in part, explain why significant functional recovery was never obtained after ChABC and/or ChAC treatments.

To explore the role of TSG-6 in TBI, specifically astrogliosis, we compared the differences in injury outcomes in $T s g-6^{-/-}$and $T s g-6^{+/-}$mice after PBIs. Our data show an increase in TSG-6 expression in the injured hemisphere of $T s g-\sigma^{+/-}$mice after TBI. This increase in expression after CNS insults supports our earlier findings in a rat model that astrocytes secrete high levels of TSG-6 upon injury, which aids in the formation of a specialized HA/HC/TSG-6 matrix during an inflammatory response (47). As TSG-6 is known for having anti-inflammatory properties, to further study whether high levels of TSG-6 served a purpose of rapidly suppressing inflammation after injury, we performed similar penetrating injuries in Tsg$6^{-/-}$mice. We used immunohistochemistry and RNA expression analyses of inflammatory and glial scar markers to elucidate the outcome during the acute phase as well as chronic phase of TBI. During the acute phase of injury, from increased astrocyte activation and inflammatory markers, there is increased inflammation in $\mathrm{Tsg}^{-6^{-/-}}$mice, suggesting that the loss of TSG-6 results in a greater inflammatory response. Moreover, during the chronic phase of injury, unrestricted inflammatory response is observed throughout the right brain hemisphere and does not seem to be limited to the injury site as is common with glial scar formation. Thus, injured $T s g-6^{-/-}$mice appear to experience more severe tissue damage 
than their $T s g-6^{+/-}$counterpart both within and surrounding the injury site. Thus, the loss of TSG- 6 allows the damage to spread from the injury site to neighboring healthy tissues. We postulate that the cause of such widespread damage is due to the lack of the specialized HA-TSG6 or HA/HC/TSG-6 matrix that could possibly stabilize the glial scar thereby protecting adjacent tissues from further damage. This hypothesis is further supported by the increase in CSPGs and HA biosynthesis in $T s g-6^{-/-}$mice. Specifically, these mice show increased Has2, Chst11 and Chst12 expression levels in tissues collected after the onset of glial scarring and also during the chronic phase of astrogliosis. This increase in expression was not only observed at the injury site but throughout the whole hemisphere, again, suggesting that the tissue damage can spread away from injury site with the absence of TSG-6. Collectively, these results demonstrate that the loss of TSG-6 leads to a more severe inflammatory response and consequently increased scarring after TBI. Thus our results support the hypothesis that was put forward by many groups over the past decade that preventing the formation of the glial scar leads to inflammation and damage beyond the injury site. We also provide experimental evidence that shows that the glial scar functions to restrict the damage to the injury site. Importantly, these findings should be taken into account when attempts are made to disrupt the glial scar as a means to promote neuronal regeneration, since preventing formation of the glial scar may not have the beneficial outcomes as previously presumed.

\section{Conclusion}

Our results show that TSG-6 has an anti-inflammatory role in the glial scar. Our study further supports the hypothesis that the glial scar forms a protective border surrounding the injury site thereby preventing the spread of inflammation and damage beyond the injury site.

\section{Abbreviations}

TBI: Traumatic brain injury

TNF: Tumor necrosis factor

TSGP-6: TNF-stimulated gene-6

GFAP: Glial Fibrillary Acidic Protein

VIM: Vimentin

CSPGs: Chondroitin sulfate proteoglycans

STAT3: Signal transducer and activator of Transcription 3

HA: Hyaluronan

GAGS: Glycosaminoglycans

CNS: Central nervous system 
HC: Heavy Chain

ITI or lal: Inter-alpha inhibitor

hUMSCs: Human umbilical cord mesenchymal stem cells

PTX3: Pentraxin-3

NFKB: Nuclear factor kappa-light-chain-enhancer

IL1 $\beta$ : Interleukin 1 beta

Ccl5: Chemokine (C-C motif) ligand 1 or Rantes

HAS: Hyaluronan synthase

Chst: Carbohydrate (chondroitin 4) sulfotransferase

\section{Declarations}

\section{Ethics approval}

Experimental procedures for handling the mice animal care were in accordance to regulations of the National Institute of Health and were approved by the Institutional Animal Care and Use Committee, University of Houston.

\section{Consent for publication}

Not applicable

\section{Availability of data and materials}

The datasets used and/or analyzed during the current study are available from the corresponding author on reasonable request.

\section{Competing interests}

The authors declare that they have no competing interests.

\section{Funding Sources}

This study was supported by start-up funds from the University of Houston to VJCT, The Mizutani Foundation grant to VJCT and the National Institute of Health/National Eye Institute R01 EY029289 to VJCT and Core grant P30 EY07551.

\section{Authors' contributions}


$\mathrm{VH}$ and VCT generated the hypothesis and experimental design. VCT, KNM and MS contributed to the experimental design. KNM, MS, AN and VCT conducted the experiments and helped with the data analysis. All authors read and approved the final manuscript.

\section{Acknowledgements}

The authors would like to thank Denise Lerma and Nicole Grimmes who participated in the study. The authors are in debt to Tarsis F. Gesteira and Yvette May Coulson- Thomas for their invaluable help throughout the study. Transgenic Tsg-6 null mice (Tnfip6 $\left.6^{D / D}\right)$ were kindly provided by Dr. Mark Lauer.

\section{Author Details}

${ }^{1}$ College of Optometry, University of Houston, Houston, Texas, USA.

${ }^{2}$ Cleveland Clinic, Cleveland, Ohio, USA

\section{References}

1. Hyder AA, Wunderlich CA, Puvanachandra P, Gururaj G, Kobusingye OC. The impact of traumatic brain injuries: a global perspective. NeuroRehabilitation. 2007;

2. Bose P, Hou J, Thompson FJ. Traumatic Brain Injury (TBI)-Induced Spasticity: Neurobiology, Treatment, and Rehabilitation. Brain Neurotrauma: Molecular, Neuropsychological, and Rehabilitation Aspects. 2015.

3. Blennow K, Brody DL, Kochanek PM, Levin H, McKee A, Ribbers GM, et al. Traumatic brain injuries. Nat Rev Dis Prim. 2016;

4. Graham DI, Mcintosh TK, Maxwell WL, Nicoll JAR. Recent advances in neurotrauma. Journal of Neuropathology and Experimental Neurology. 2000.

5. Zaninotto ALC, Costa BT, Ferreira IS, French M, Paiva WS, Fregni F. Traumatic brain injury. In: Neuromethods. 2018.

6. Burda JE, Bernstein AM, Sofroniew M V. Astrocyte roles in traumatic brain injury. Experimental Neurology. 2016.

7. Kovacs SK, Leonessa F, Ling GSF. Blast TBI models, neuropathology, and implications for seizure risk. Frontiers in Neurology. 2014.

8. Sharp DJ, Scott G, Leech R. Network dysfunction after traumatic brain injury. Nature Reviews Neurology. 2014.

9. Fakhran S, Alhilali L. Neurodegenerative changes after mild traumatic brain injury. In: Concussion. 2012.

10. NAGAHIRO S, MIZOBUCHI Y. Current Topics in Sports-related Head Injuries: A Review. Neurol Med Chir (Tokyo). 2014; 
11. Jordan BD. The clinical spectrum of sport-related traumatic brain injury. Nature Reviews Neurology. 2013.

12. Costanza A, Weber K, Gandy S, Bouras C, Hof PR, Giannakopoulos P, et al. Review: Contact sportrelated chronic traumatic encephalopathy in the elderly: Clinical expression and structural substrates. Neuropathology and Applied Neurobiology. 2011.

13. McAllister T, McCrea M. Long-Term Cognitive and Neuropsychiatric Consequences of Repetitive Concussion and Head-Impact Exposure. J Athl Train. 2017;

14. Sofroniew M V., Vinters H V. Astrocytes: Biology and pathology. Acta Neuropathologica. 2010.

15. Sofroniew M V. Astrogliosis. Cold Spring Harb Perspect Biol. 2015;

16. Sofroniew M V. Reactive astrocytes in neural repair and protection. Neuroscientist. 2005.

17. Smith PD, Coulson-Thomas VJ, Foscarin S, Kwok JCF, Fawcett JW. "GAG-ing with the neuron": The role of glycosaminoglycan patterning in the central nervous system. Experimental Neurology. 2015.

18. McGraw J, Hiebert GW, Steeves JD. Modulating astrogliosis after neurotrauma. Journal of Neuroscience Research. 2001.

19. Kawano H, Kimura-Kuroda J, Komuta Y, Yoshioka N, Li HP, Kawamura K, et al. Role of the lesion scar in the response to damage and repair of the central nervous system. Cell and Tissue Research. 2012.

20. Burda JE, Sofroniew M V. Reactive gliosis and the multicellular response to CNS damage and disease. Neuron. 2014.

21. Sofroniew M V. Molecular dissection of reactive astrogliosis and glial scar formation. Trends in Neurosciences. 2009.

22. Davies SJA, Goucher DR, Doller C, Silver J. Robust Regeneration of Adult Sensory Axons in Degenerating White Matter of the Adult Rat Spinal Cord. J Neurosci. 2018;

23. McKeon RJ, Jurynec MJ, Buck CR. The Chondroitin Sulfate Proteoglycans Neurocan and Phosphacan Are Expressed by Reactive Astrocytes in the Chronic CNS Glial Scar. J Neurosci. 2018;

24. Okada S, Nakamura M, Katoh H, Miyao T, Shimazaki T, Ishii K, et al. Conditional ablation of Stat3 or Socs3 discloses a dual role for reactive astrocytes after spinal cord injury. Nat Med. 2006;

25. Voskuhl RR, Peterson RS, Song B, Ao Y, Morales LBJ, Tiwari-Woodruff S, et al. Reactive Astrocytes Form Scar-Like Perivascular Barriers to Leukocytes during Adaptive Immune Inflammation of the CNS. J Neurosci. 2009;

26. Wanner IB, Anderson MA, Song B, Levine J, Fernandez A, Gray-Thompson Z, et al. Glial Scar Borders Are Formed by Newly Proliferated, Elongated Astrocytes That Interact to Corral Inflammatory and Fibrotic Cells via STAT3-Dependent Mechanisms after Spinal Cord Injury. J Neurosci. 2013;

27. Faulkner JR. Reactive Astrocytes Protect Tissue and Preserve Function after Spinal Cord Injury. J Neurosci. 2004;

28. Myer DJ, Gurkoff GG, Lee SM, Hovda DA, Sofroniew M V. Essential protective roles of reactive astrocytes in traumatic brain injury. Brain. 2006; 
29. Fitch MT, Silver J. CNS injury, glial scars, and inflammation: Inhibitory extracellular matrices and regeneration failure. Experimental Neurology. 2008.

30. Massey JM, Amps J, Viapiano MS, Matthews RT, Wagoner MR, Whitaker CM, et al. Increased chondroitin sulfate proteoglycan expression in denervated brainstem targets following spinal cord injury creates a barrier to axonal regeneration overcome by chondroitinase $A B C$ and neurotrophin-3. Exp Neurol. 2008;

31. Tan AM. Antibodies against the NG2 Proteoglycan Promote the Regeneration of Sensory Axons within the Dorsal Columns of the Spinal Cord. J Neurosci. 2006;

32. Bradbury EJ, Carter LM. Manipulating the glial scar: Chondroitinase $A B C$ as a therapy for spinal cord injury. Brain Research Bulletin. 2011.

33. Pekny M, Wilhelmsson $U$, Pekna M. The dual role of astrocyte activation and reactive gliosis. Neuroscience Letters. 2014.

34. Wilhelmsson U. Absence of Glial Fibrillary Acidic Protein and Vimentin Prevents Hypertrophy of Astrocytic Processes and Improves Post-Traumatic Regeneration. J Neurosci. 2004;

35. Pekny M. Astrocytic intermediate filaments: Lessons from GFAP and vimentin knock-out mice. Prog Brain Res. 2001;

36. Pekny M, Johansson CB, Eliasson C, Stakeberg J, Wallén Å, Perlmann T, et al. Abnormal reaction to central nervous system injury in mice lacking glial fibrillary acidic protein and vimentin. J Cell Biol. 1999;

37. Bush TG, Puvanachandra N, Horner CH, Polito A, Ostenfeld T, Svendsen CN, et al. Leukocyte infiltration, neuronal degeneration, and neurite outgrowth after ablation of scar-forming, reactive astrocytes in adult transgenic mice. Neuron. 1999;

38. Herrmann JE, Imura T, Song B, Qi J, Ao Y, Nguyen TK, et al. STAT3 is a critical regulator of astrogliosis and scar formation after spinal cord injury. J Neurosci. 2008;

39. Faulkner JR, Herrmann JE, Woo MJ, Tansey KE, Doan NB, Sofroniew M V. Reactive Astrocytes Protect Tissue and Preserve Function after Spinal Cord Injury. J Neurosci. 2004;

40. Fan H, Zhang K, Shan L, Kuang F, Chen K, Zhu K, et al. Reactive astrocytes undergo M1 microglia/macrohpages-induced necroptosis in spinal cord injury. Mol Neurodegener. 2016;

41. Gesteira TF, Coulson-Thomas YM, Coulson-Thomas VJ. Anti-inflammatory properties of the glial scar. Neural Regeneration Research. 2016.

42. Milner CM. TSG-6: a multifunctional protein associated with inflammation. J Cell Sci. 2003;

43. Bradbury EJ, Moon LDF, Popat RJ, King VR, Bennett GS, Patel PN, et al. Chondroitinase ABC promotes functional recovery after spinal cord injury. Nature. 2002;

44. Elkin BS, Shaik MA, Morrison B. Chondroitinase $A B C$ reduces brain tissue swelling in vitro. J Neurotrauma. 2011;28(11):2277-85.

45. Massey JM, Hubscher CH, Wagoner MR, Decker JA, Amps J, Silver J, et al. Chondroitinase ABC digestion of the perineuronal net promotes functional collateral sprouting in the cuneate nucleus after cervical spinal cord injury. J Neurosci. 2006; 
46. Moon LDF, Asher RA, Fawcett JW. Limited growth of severed CNS axons after treatment of adult rat brain with hyaluronidase. J Neurosci Res. 2003;71(1):23-37.

47. Coulson- Thomas VJ, Lauer ME, Soleman S, Zhao C, Hascall VC, Day AJ, et al. TSG-6 is constitutively expressed in adult CNS and associated with astrocyte-mediated glial scar formation following spinal cord injury. J Biol Chem. 2016;

48. Carrette O, Nemade R V., Day AJ, Brickner A, Larsen WJ. TSG-6 Is Concentrated in the Extracellular Matrix of Mouse Cumulus Oocyte Complexes Through Hyaluronan and Inter-Alpha-Inhibitor Binding1. Biol Reprod. 2001;

49. Salustri A, Yanagishita M, Hascall VC. Synthesis and accumulation of hyaluronic acid and proteoglycans in the mouse cumulus cell-oocyte complex during follicle-stimulating hormone-induced mucification. J Biol Chem. 1989;

50. Salustri A, Yanagishita M, Underhill CB, Laurent TC, Hascall VC. Localization and synthesis of hyaluronic acid in the cumulus cells and mural granulosa cells of the preovulatory follicle. Dev Biol. 1992;

51. Camaioni A, Hascall VC, Yanagishita M, Salustri A. Effects of exogenous hyaluronic acid and serum on matrix organization and stability in the mouse cumulus cell-oocyte complex. J Biol Chem. 1993;

52. Fulop C. Impaired cumulus mucification and female sterility in tumor necrosis factor-induced protein6 deficient mice. Development. 2003;

53. Stober VP, Johnson CG, Majors A, Lauer ME, Cali V, Midura RJ, et al. TNF-stimulated gene 6 promotes formation of hyaluronan-inter-a-inhibitor heavy chain complexes necessary for ozoneinduced airway hyperresponsiveness. J Biol Chem. 2017;

54. Lauer ME, Glant TT, Mikecz K, DeAngelis PL, Haller FM, Husni ME, et al. Irreversible heavy chain transfer to hyaluronan oligosaccharides by tumor necrosis factor-stimulated gene-6. J Biol Chem. 2013;

55. Petrey AC, De La Motte CA. Thrombin Cleavage of Inter-a-inhibitor Heavy Chain 1 Regulates Leukocyte Binding to an Inflammatory Hyaluronan Matrix. J Biol Chem. 2016;

56. Hill DR, Rho HK, Kessler SP, Amin R, Homer CR, McDonald C, et al. Human milk hyaluronan enhances innate defense of the intestinal epithelium. J Biol Chem. 2013;

57. Baranova NS, Foulcer SJ, Briggs DC, Tilakaratna V, Enghild JJ, Milner CM, et al. Inter-a-inhibitor impairs TSG-6-induced hyaluronan cross-linking. J Biol Chem. 2013;

58. Kessler SP, Obery DR, De La Motte C. Hyaluronan Synthase 3 Null Mice Exhibit Decreased Intestinal Inflammation and Tissue Damage in the DSS-Induced Colitis Model. Int J Cell Biol. 2015;

59. Lim Y, Bendelja K, Opal SM, Siryaporn E, Hixson DC, Palardy JE. Correlation between Mortality and the Levels of Inter-Alpha Inhibitors in the Plasma of Patients with Severe Sepsis. J Infect Dis. 2003;

60. Schmidt EP, Overdier KH, Sun X, Lin L, Liu X, Yang Y, et al. Urinary glycosaminoglycans predict outcomes in septic shock and acute respiratory distress syndrome. Am J Respir Crit Care Med. 2016;

61. Coulson-Thomas VJ, Gesteira TF, Hascall V, Kao W. Umbilical cord mesenchymal stem cells suppress host rejection: The role of the glycocalyx. J Biol Chem. 2014; 
62. S.M. D, S. K-A. Chondroitin sulfate proteoglycans: Key modulators in the developing and pathologic central nervous system. Exp Neurol. 2015;

63. McKeon RJ, Höke A, Silver J. Injury-induced proteoglycans inhibit the potential for laminin-mediated axon growth on astrocytic scars. Exp Neurol. 1995;

64. Silver J, Miller JH. Regeneration beyond the glial scar. Nature Reviews Neuroscience. 2004.

65. McKeon RJ, Schreiber RC, Rudge JS, Silver J. Reduction of neurite outgrowth in a model of glial scarring following CNS injury is correlated with the expression of inhibitory molecules on reactive astrocytes. J Neurosci. 1991;

66. Foerster AP. Spontaneous regeneration of cut axons in adult rat brain. J Comp Neurol. 1982;210(4):335-56.

67. Brückner G, Bringmann A, Härtig W, Köppe G, Delpech B, Brauer K. Acute and long-lasting changes in extracellular-matrix chondroitin-sulphate proteoglycans induced by injection of chondroitinase $A B C$ in the adult rat brain. Exp Brain Res. 1998;121(3):300-10.

68. Filous AR, Miller JH, Coulson-Thomas YM, Horn KP, Alilain WJ, Silver J. Immature astrocytes promote CNS axonal regeneration when combined with chondroitinase ABC. Dev Neurobiol. 2010;70(12):82641.

69. Moon LDF, Asher RA, Rhodes KE, Fawcett JW. Regeneration of CNS axons back to their target following treatment of adult rat brain with chondroitinase ABC. Nat Neurosci. 2001;

70. Busch SA, Silver J. The role of extracellular matrix in CNS regeneration. Current Opinion in Neurobiology. 2007.

71. Klapka N, Hermanns S, Straten G, Masanneck C, Duis S, Hamers FPT, et al. Suppression of fibrous scarring in spinal cord injury of rat promotes long-distance regeneration of corticospinal tract axons, rescue of primary motoneurons in somatosensory cortex and significant functional recovery. Eur $\mathrm{J}$ Neurosci. 2005;

72. Milner CM, Tongsoongnoen W, Rugg MS, Day AJ. The molecular basis of inter-a-inhibitor heavy chain transfer on to hyaluronan: Figure 1. Biochem Soc Trans. 2007;

73. Getting SJ, Mahoney DJ, Cao T, Rugg MS, Fries E, Milner CM, et al. The link module from human TSG6 inhibits neutrophil migration in a hyaluronan- and inter-a-inhibitor-independent manner. J Biol Chem. 2002;

74. Baranova NS, Nilebäck E, Haller FM, Briggs DC, Svedhem S, Day AJ, et al. The inflammationassociated protein TSG-6 cross-links hyaluronan via hyaluronan-induced TSG-6 oligomers. J Biol Chem. 2011;

75. Higman VA, Briggs DC, Mahoney DJ, Blundell CD, Sattelle BM, Dyer DP, et al. A refined model for the TSG-6 link module in complex with hyaluronan: Use of defined oligosaccharides to probe structure and function. J Biol Chem. 2014;

76. Martin J, Midgley A, Meran S, Woods E, Bowen T, Phillips AO, et al. Tumor necrosis factor-stimulated gene 6 (TSG-6)-mediated interactions with the inter-a-inhibitor heavy chain 5 facilitate tumor growth factor $\beta 1$ (TGF $\beta 1$ )-dependent fibroblast to myofibroblast differentiation. J Biol Chem. 2016; 
Figures
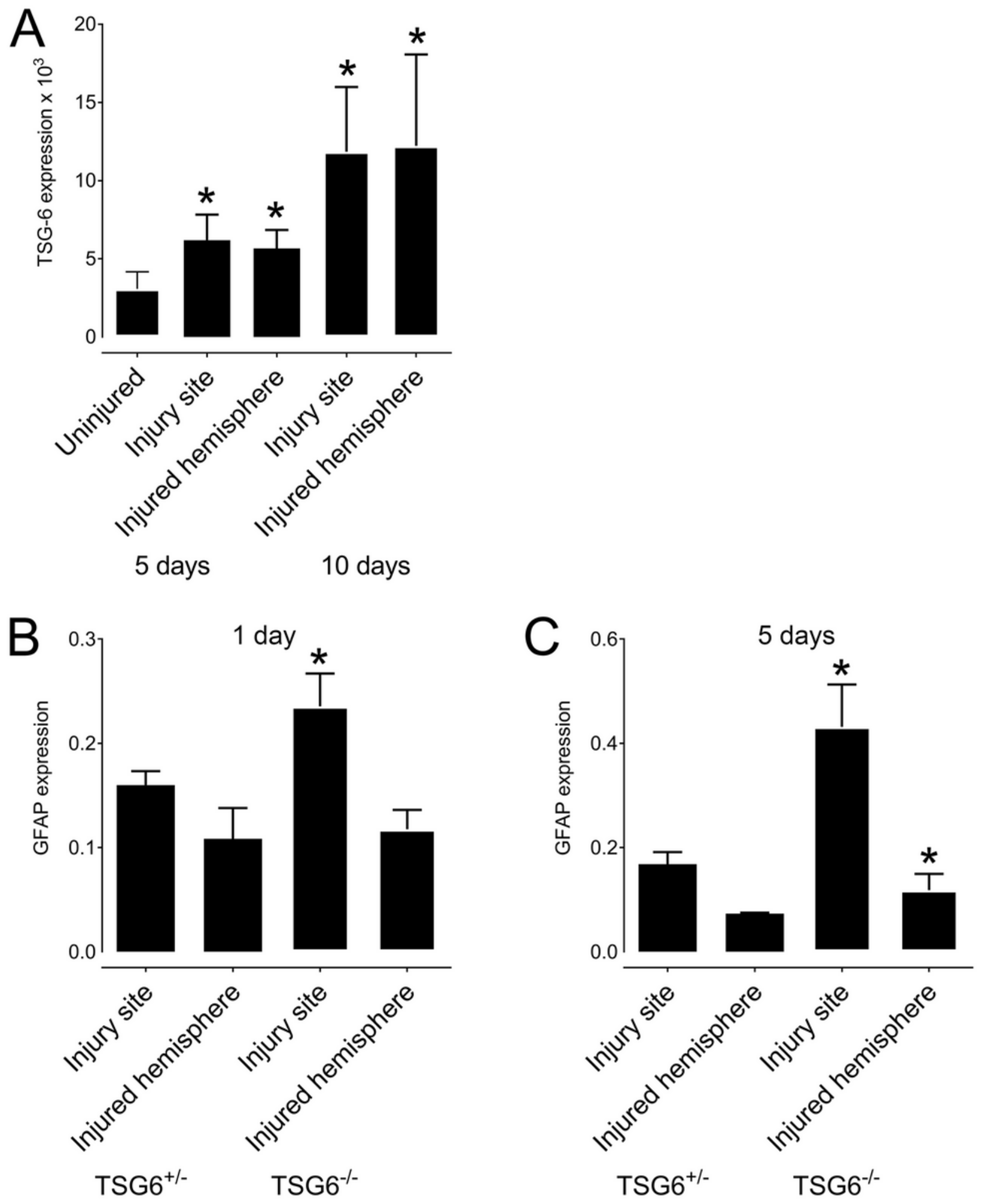

Figure 1

TSG- 6 and GFAP expression after PBI. TSG- 6 and GFAP mRNA expressions were quantified in the injury site and the injured hemisphere after PBI. (A) TSG-6-/+ mice were submitted to PBI, and the injury site and remaining injured hemisphere were collected 5 and 10 days after injury for analysis of TSG- 6 expression. 
(B and C) TSG-6-/+ and TSG-6-/- mice were subjected to PBI, and the injury site and remaining injured hemisphere were collected 1 day $(B)$ and 5 days $(C)$ after injury. * $=p \leq 0.05$ comparing TSG-6-/+ and TSG6-/- mice.

1 day
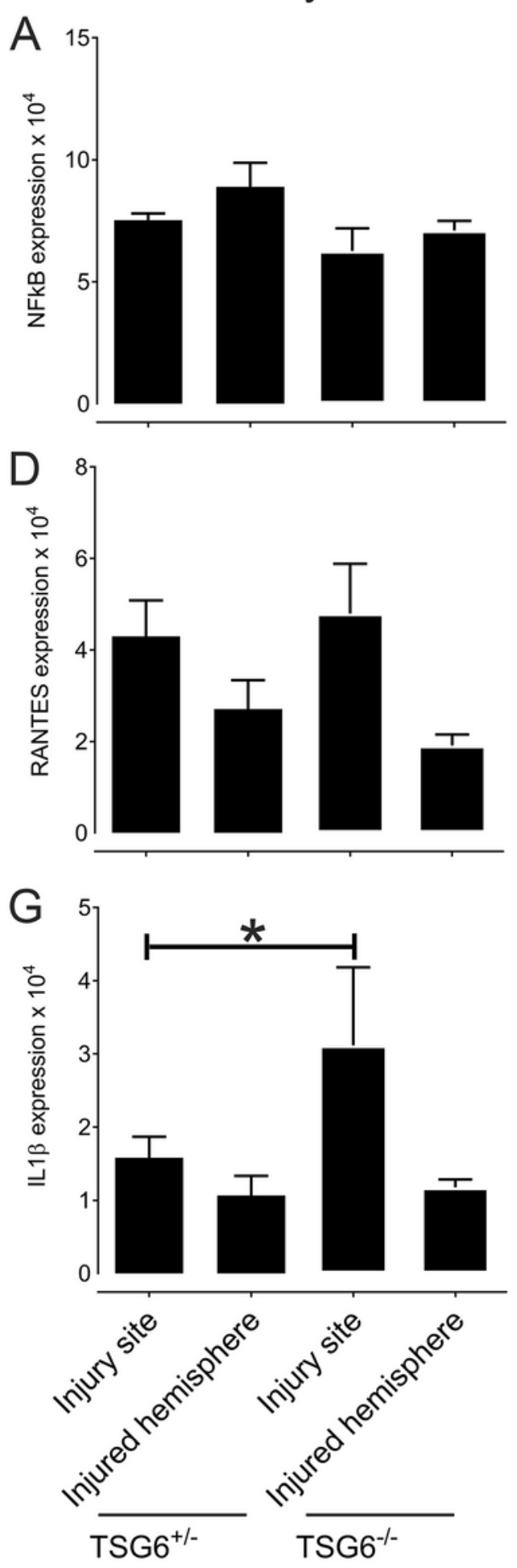

5 days
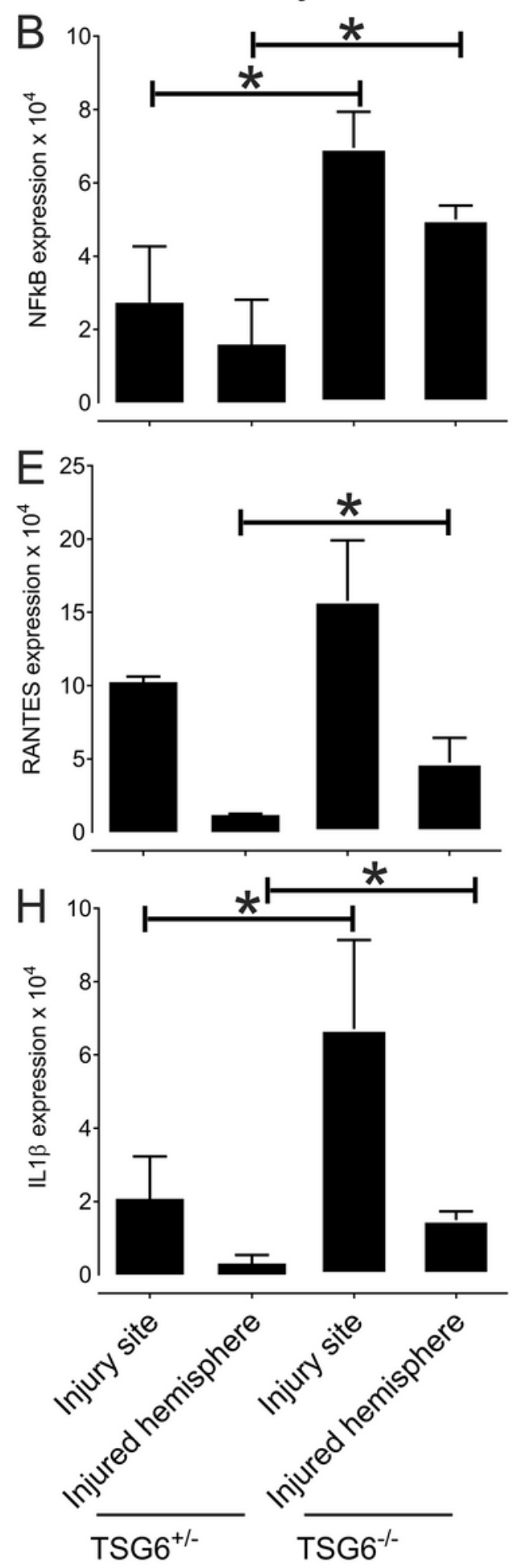

10 days
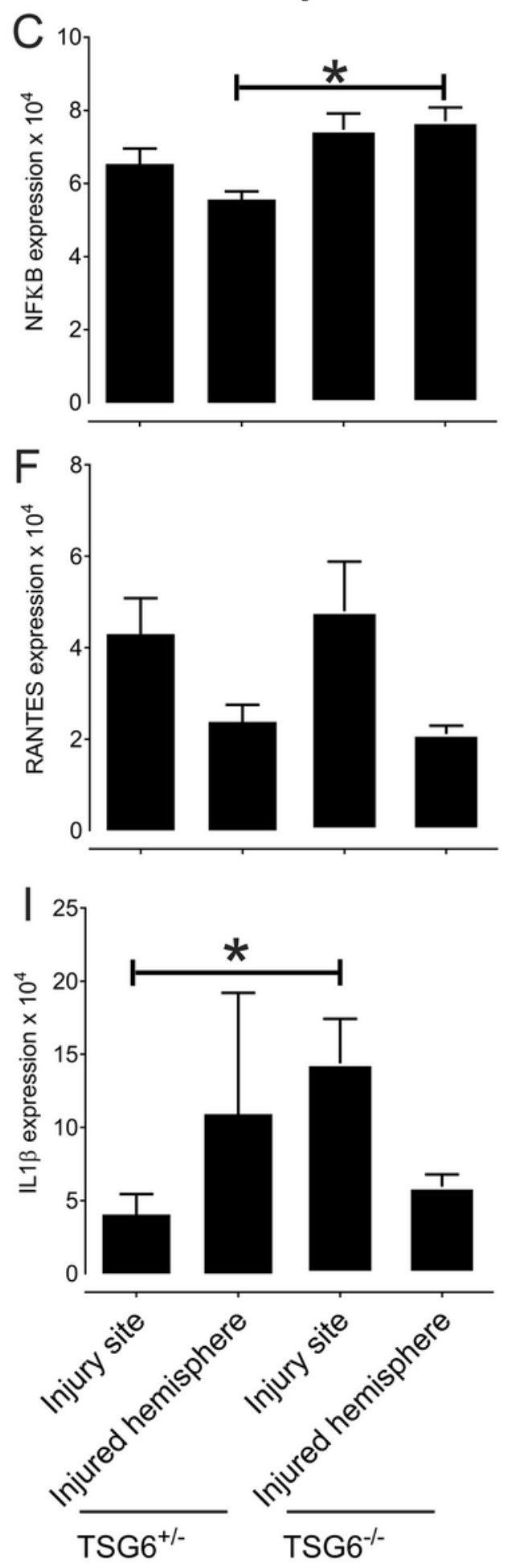

Figure 3

Analysis of inflammatory markers after PBI. NFロB, RANTES and IL1囚 mRNA expressions were quantified in the injury site and the injured hemisphere after PBI. TSG-6-/+ and TSG-6-/- mice were subjected to PBI and 
the injury site and remaining injured hemisphere were collected 1, 5 and 10 days after injury. mRNA was extracted and subjected to real-time PCR analysis for NFロB (A, B and C), RANTES (D, E and F) and IL1区 (G, $\mathrm{H}$ and I) mRNA expression. ${ }^{*}=\mathrm{p} \leq 0.05$ comparing TSG-6-/+ and TSG-6-/- mice.

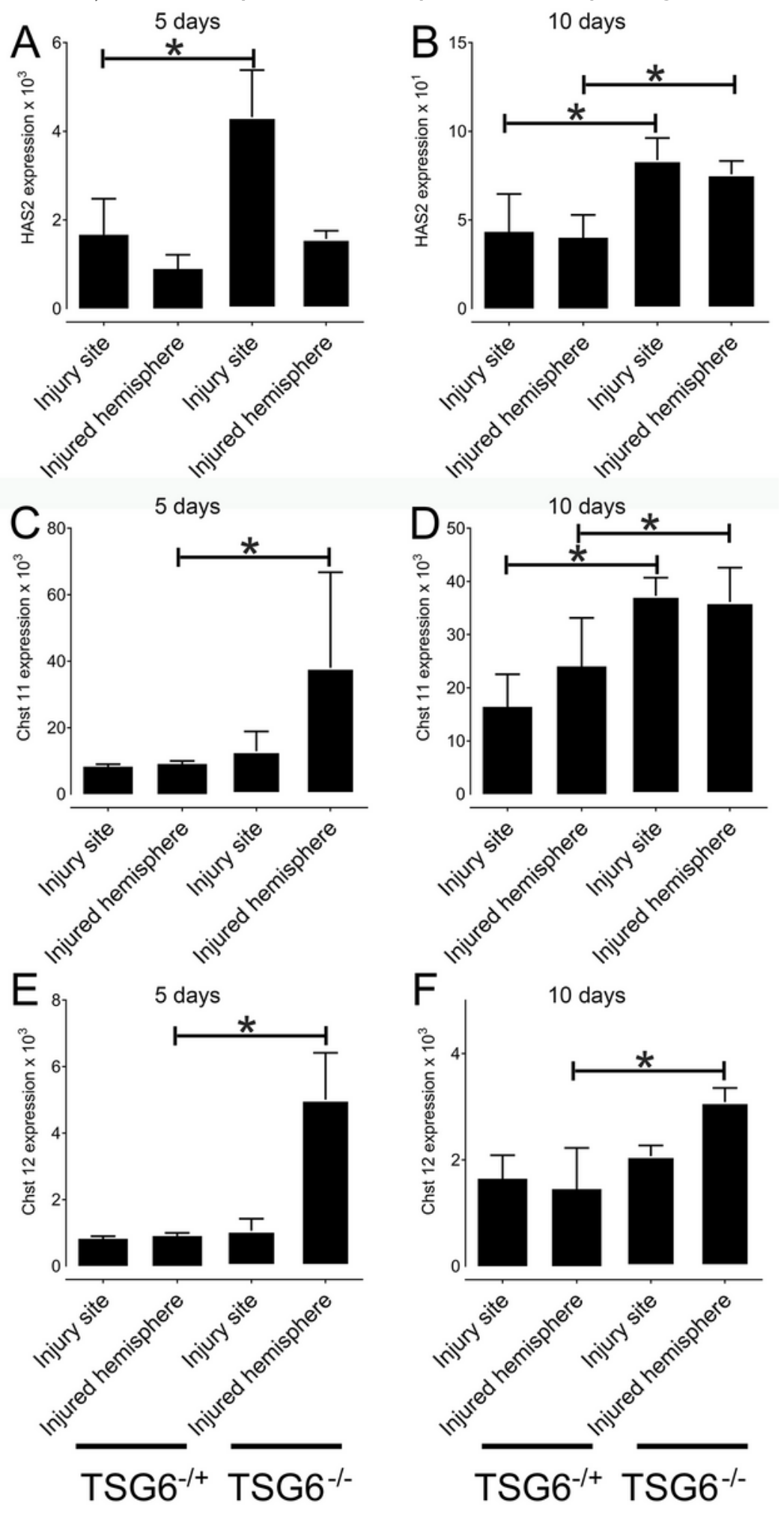

Figure 5

Analysis of glial scar ECM components after PBI. HAS2, Chst 11 and Chest 12 mRNA expression levels were quantified in the injury site and the injured hemisphere after PBI. TSG-6-/+ and TSG-6-/- mice were 
subjected to $\mathrm{PBI}$, and the injury site and remaining injured hemisphere were collected 5 and 10 days after injury. mRNA was extracted and subjected to real-time PCR analysis for HAS2 (A and B), Chst11 (C and D) and Chest 12 (E and F) mRNA expression. * $=p \leq 0.05$ comparing TSG-6-/+ and TSG-6-/- mice.
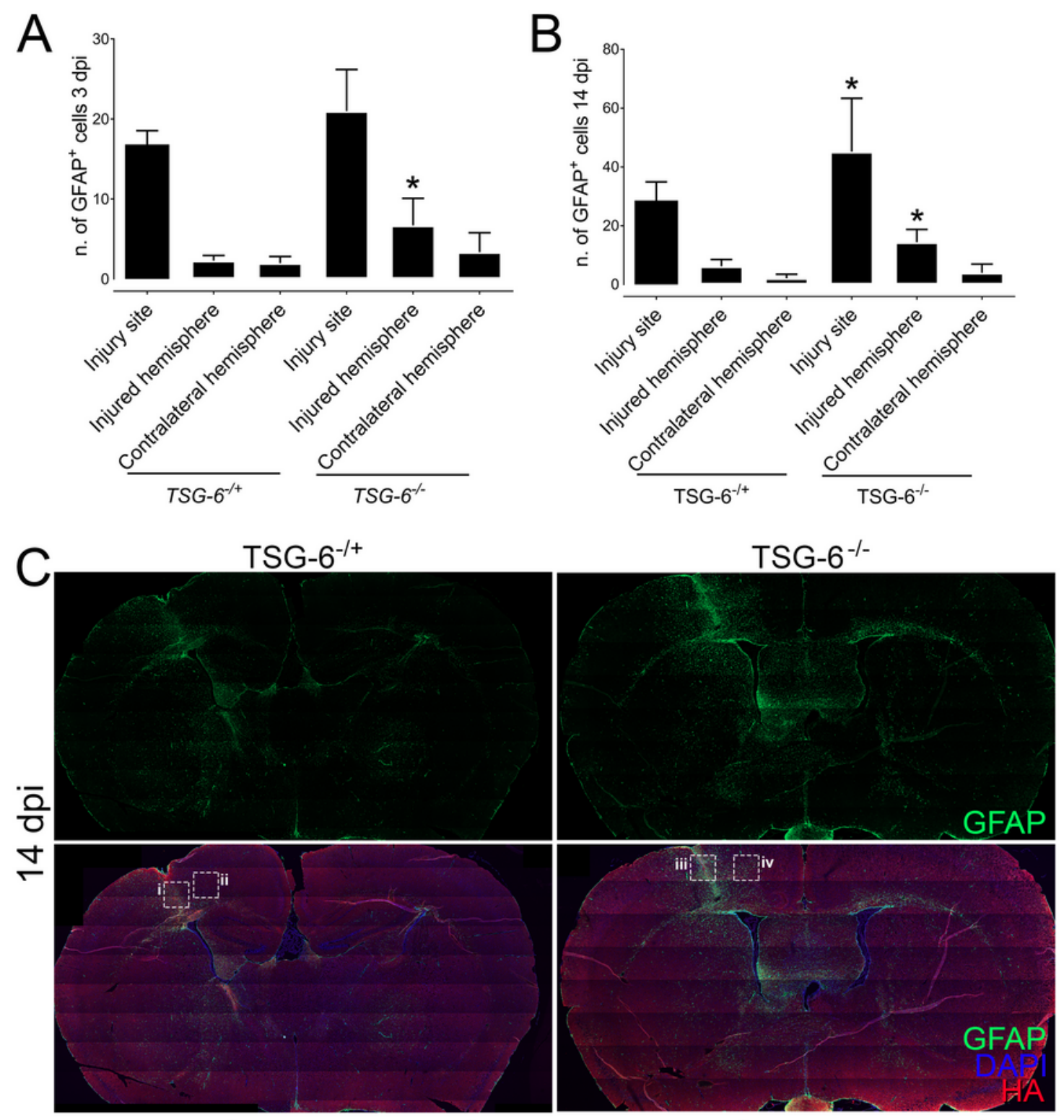

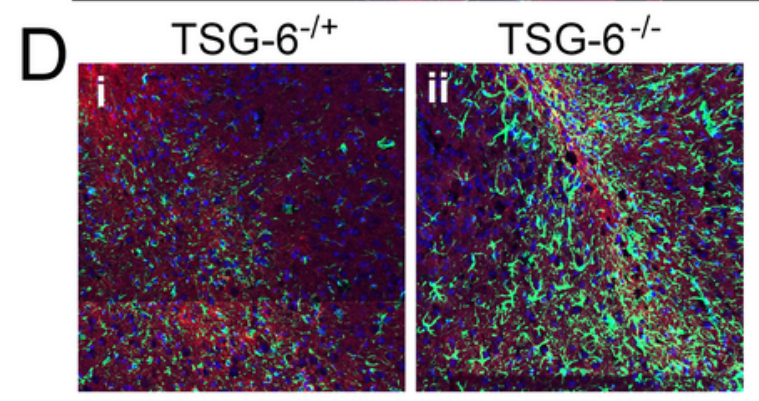

Injury site

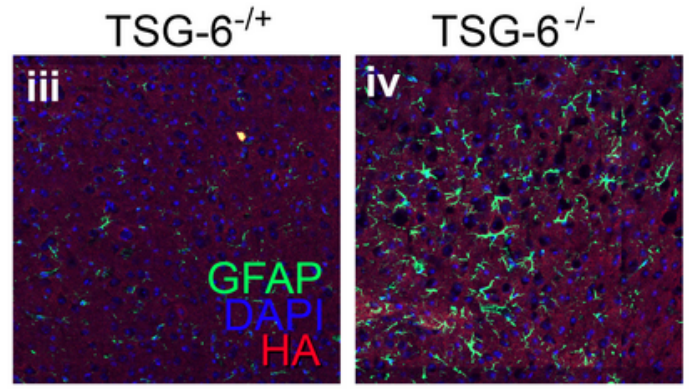

Away from the injury site

\section{Figure 7}

Analysis of astrocyte activation and recruitment after PBI. Brain sections from TSG-6+/- and TSG-6-/- mice were analyzed by immunohistochemistry. Astrocytes were identified with anti-GFAP (green) and the glial 
scar with HABP (red). Nuclei were counterstained with DAPI (blue). Z-stacks were captured of the entire brain section using the tilling mode, and images were stitched together using Zen software. Thereafter, the number of astrocytes was counted within the injury site, within the injured hemisphere and in the contralateral hemisphere of brains $3(\mathrm{~A})$ and $14 \mathrm{dpi}(\mathrm{B})$. The distribution of astrocytes throughout the brain sections shows that in TSG-6-/- mice the increase in astrocytes is not restricted to the injury site (C). Magnified images of the areas demarcated in (C) can be seen in (D). At least 3 mice were analyzed per genotype for each time point. * $=p \leq 0.05$ comparing TSG-6-/+ and TSG-6-/- mice. 